\title{
Electronic Patient-Physician Communication: Problems and Promise
}

\section{Citation}

Mandl, Kenneth D., Isaac S. Kohane, and Allan M. Brandt. 1998. Electronic patient-physician communication: Problems and promise. Annals of Internal Medicine 129(6): 495-500.

\section{Published Version}

http://www.annals.org/

\section{Permanent link}

http://nrs.harvard.edu/urn-3:HUL.InstRepos:3382980

\section{Terms of Use}

This article was downloaded from Harvard University's DASH repository, and is made available under the terms and conditions applicable to Other Posted Material, as set forth at http:// nrs.harvard.edu/urn-3:HUL.InstRepos:dash.current.terms-of-use\#LAA

\section{Share Your Story}

The Harvard community has made this article openly available.

Please share how this access benefits you. Submit a story.

\section{Accessibility}




\title{
Electronic Patient-Physician Communication: Problems and Promise
}

\author{
Kenneth D. Mandl, MD, MPH; Isaac S. Kohane, MD, PhD; and Allan M. Brandt, PhD
}

A critical mass of Internet users will soon enable wide diffusion of electronic communication within medical practice. E-mail between physicians and patients offers important opportunities for better communication. Linking patients and physicians through e-mail may increase the involvement of patients in supervising and documenting their own health care, processes that may activate patients and contribute to improved health. These new linkages may have profound implications for the patientphysician relationship. Although the federal government proposes regulation of telemedicine technologies and medical software, communications technologies are evolving under less scrutiny. Unless these technologies are implemented with substantial forethought, they may disturb delicate balances in the patient-physician relationship, widen social disparities in health outcomes, and create barriers to access to health care.

This paper seeks to identify the promise and pitfalls of electronic patient-physician communication before such technology becomes widely distributed. A research agenda is proposed that would provide data that are useful for careful shaping of the communications infrastructure. The paper addresses the need to 1) define appropriate use of the various modes of patient-physician communication, 2) ensure the security and confidentiality of patient information, 3) create user interfaces that guide patients in effective use of the technology, 4) proactively assess medicolegal liability, and 5) ensure access to the technology by a multicultural, multilingual population with varying degrees of literacy.

Ann Intern Med. 1998;129:495-500.

From Children's Hospital and Harvard Medical School, Boston, and Massachusetts Institute of Technology, Cambridge, Massachusetts. For current author addresses, see end of text.

$\mathrm{T}$ he introduction of the telephone into medical practice in the last decades of the 19th century was greeted with both celebration and trepidation. Invented in 1876 by Alexander Graham Bell, the telephone was commercially introduced in the late 1870s. It was not until World War I, however, that the telephone became a common utility (1). Although some physicians heralded the advantages of efficiency and accessibility that the telephone offered, others expressed concerns about being overwhelmed by patients seeking over-the-telephone care, the safety of telephone diagnosis, and problems of privacy. By the mid-1920s, the telephone was fully integrated into physician practice, as it was in broader society. The telephone had become a mandatory medical technology, as central to practice as the stethoscope and sphygmomanometer (2).

We are again on the threshold of a dramatic expansion in communications technology that may have profound effects on the patient-physician relationship and the practice of medicine. We are approaching a critical mass of Internet users that will lead to a wide diffusion of electronic communications within medical practice $(3,4)$. The American Medical Informatics Association recently published recommendations to guide computer-based communications between clinicians and patients (5). Little attention, however, is being paid to the implications of direct electronic linkages between physicians and patients. Unless implemented with substantial forethought, these linkages may disturb delicate balances in the patient-physician relationship, widen social disparities in health outcomes, and create barriers to access. We attempt to identify some of the promise and pitfalls of electronic patientphysician communication before such technology becomes widely distributed. Furthermore, we propose a research agenda to provide data that is useful for careful shaping of the communications infrastructure.

\section{The Present State of Electronic Medicine}

Internet technologies have become useful tools for medical practice. Online, physicians can search the medical literature and find both synoptic and full-text medical journal content (6-10). Patients have access to medical information, self-help and support groups, and even medical experts (11-13). The World Wide Web can be used to link patient data across multiple institutions for retrieval by providers at the point of service or by researchers (14, 15). The Internet also allows visual contact. For example, the National Library of Medicine's Tele-

See related article on pp 441-449. 
medicine Initiative enables parents of premature infants to videoconference from home with the neonatal intensive care unit (16).

Although the Internet community has always resisted national and international efforts to regulate its structure or content $(17,18)$, a motion is under way to impose an organizational structure and monitor the quality of the largely unchecked, unstructured, and unregulated volumes of medical information found on the Web (19-21). Journals, professional organizations $(19,21,22)$, and the federal government (23-27) have proposed monitoring medical information on the Internet and regulating telemedicine technologies. Early federal efforts along these lines include the Congressional Telecommunications Act of 1996 (28) as well as the U.S. Food and Drug Administration's proposed oversight of telemedicine applications and clinical software (22).

Direct electronic communication linkages between physicians and patients are also evolving, although so far these are under considerably less scrutiny. One such linkage is simple e-mail. Approximately 40000000 persons in the United States use the Internet (29), and anecdotal reports are emerging of its use for communication between physicians and patients. In university health service settings, in which both patients and physicians tend to have access to e-mail, an initial investigation has demonstrated the potential for widespread acceptance of electronic patient-physician communications by this method $(30,31)$.

\section{The Promise of E-Mail}

E-mail can connect physicians with patients, thereby increasing access to care, enhancing patient education, augmenting screening programs, and improving adherence to treatment plans. Barriers to access often arise simply because physicians can be difficult to reach (32). Unlike telephone conversations, which require both parties to be available at the same time, e-mail, like voice mail, is an asynchronous mode of communication $(33,34)$, essentially creating continuous access to the health care system.

A widening gap is developing between the crucial need for transmitting more information and the relatively few and often brief face-to-face opportunities for communication between physicians and patients. The quality of these personal encounters is further diminished by the need for physicians to address administrative issues, such as referrals, insurance approvals, and rejected claims, during precious contact time. Inadequate communication, now more the rule than the exception, leads to increased stress (35), diminished satisfaction $(36,37)$, decreased ad- herence to therapeutic regimens $(38,39)$, and elevated risk for malpractice claims (40). Linking patients and physicians through e-mail could increase the involvement of patients in the supervision and documentation of their own health care, processes that may activate patients and contribute to improved health (41-44). An example of electronic linkages activating patients is CHESS (Comprehensive Health Enhancement Support System), an interactive computer-based system used to support persons with AIDS and HIV infection (45).

Telephone and voice mail technologies have been effective in screening for mental disorders and substance abuse $(46,47)$. For example, computergenerated telephone reminders can improve compliance with preschool immunization visits (48). Standard e-mail or e-mail with an interface allowing structured data entry may allow more effective triage and automation of messaging than voice and video mail do.

Whether e-mail between physicians and patients can have advantages for the therapeutic relationship is a question worthy of investigation. We propose a research agenda structured around foreseeable problem areas in electronic patient-physician communication.

\section{Potential Pitfalls of E-Mail and the Need for a Research Agenda}

\section{Inappropriate Use of Communication Tools}

Health care providers need a framework for choosing the communication mode that is most appropriate for each situation. Certain kinds of communication needs may be satisfied through e-mail. For example, the patient may use e-mail to make an appointment. He or she may request general information, such as a list of low-sodium foods, or specific information, such as a modified insulin dosage based on home monitoring of glucose levels. The physician might initiate e-mail contact to conduct routine guidance and education (for example, to advise a new mother to put her baby to sleep on his back), to remind a patient of an upcoming visit, or to check on a patient's progress (for example, in a smoking cessation program). In contrast, the use of e-mail might be contraindicated in some areas, and face-to-face or telephone contact might be required. Use of e-mail by patients for urgent needs could lead to problems not being addressed quickly enough. It might also be inappropriate for physicians to use e-mail to communicate abnormal or confusing test results or to relay bad news. The diagnosis of a new problem requiring a complex and dynamic dialogue might be best handled synchronously. Face-to-face contacts are optimal for making 
many diagnoses, although elaborate telephone triage systems have been successfully used for this purpose (49). Preference for the use of e-mail will depend on the context as well as on the individual physician and patient. Just as some physicians now feel more comfortable than others with telephone medicine, so must physicians exercise personal discretion in their use of e-mail.

Used properly, e-mail may promote increased contact between physicians and patients. By increasing opportunities for communication before and after visits, e-mail might help optimize the value of personal encounters. Empirical studies, as well as expert consensus panels, are needed to develop general guidelines to direct patients and clinicians to use the contextually appropriate mode of communication. Evidence-based indications and contraindications for e-mail in the medical context must be clearly specified so that e-mail is used appropriately and does not become a barrier to telephone or face-to-face contact.

\section{Security and Confidentiality}

The confidentiality of medical information (50) and the privacy of e-mail are paramount. Patients or physicians who use e-mail in the workplace for medical interchange are not assured of confidentiality and may inadvertently expose sensitive details of illness or social circumstances to an employer. Furthermore, patients who use family e-mail accounts at home may lack privacy from spouses, children, or parents. Medical account addresses could be distinct from other personal or professional ones. Medical e-mail addresses and the messages generated through them should be reliably documented in and linked to the patient's medical record. Such linkage can be accomplished in various ways, from simply including a patient identifier to embedding a hypertext link to a Web-enabled medical record (14).

A critical decision will be the selection of a set of national health identifiers, as called for by the Health Portability Act of 1996 (23). Naive use of broadly disseminated identifiers may be unwise. For example, one proposed identifier, the Social Security number, can easily be used to identify a patient and link his or her health record to other records, such as those in financial and marketing databases (51). The Computer Science and Telecommunication Board of the National Research Council (52) recommends procedures to authenticate the user's identity and to encrypt stored or communicated data to prevent unauthorized access. Perhaps the best-developed technology for authenticating messages is public key cryptography (53). This technology requires that every participant be assigned a pair of "keys." One key is public and can be widely shared over the Internet; the other key is private.
Messages encrypted with the public key can only be decrypted by the private key and vice versa. The patient can send a message to his clinician by encrypting it with the clinician's public key so that only the clinician can decrypt the message with her private key. Similarly, a clinician can prove that she is the sender of a message (that is, she can authenticate the message) by encrypting her name (or other identifier) with her private key. The patient can then decrypt the clinician's name only with the clinician's public key. For public key cryptography to be effective in the context of a health delivery system, research into rapid and secure methods for distributing keys must be conducted. Methods by which consumers can easily apply such keys must be also be developed.

Although electronic communications must be protected from unauthorized interlopers, most violations of the confidentiality of electronic data are committed by authenticated persons (52). To prevent these breaches within organizations, further study is needed to provide a framework for developing institutional confidentiality policies, education programs, and effective legislation.

\section{Guiding Patient Communication}

A well-designed interface could guide patients as they create messages and could help triage messages received at the physician's practice. Patients could create messages by choosing from menu categories; simple scheduling questions, for example, could be automatically directed to the front desk staff, or prescription refill requests could be directed to the practice nurse. The interface should also have safety features to ensure appropriate communications. For example, the patient could be required to specify the priority of a message. If the patient indicates that the message is urgent, the system would either display a warning screen suggesting a telephone call or a visit or trigger an alert to the physician, such as an alarm or a page.

Many physicians are concerned that they could be overwhelmed by long, numerous e-mail messages from their patients. The interface could effect flow control by tracking the number and length of messages being sent by patients; when thresholds defined by the individual provider are exceeded, the system could suggest a telephone call or visit. Furthermore, the interface might passively encourage brevity by offering only a small window for text entry and thereby suggesting the appropriate length of a message. Given the flexibility afforded by connectivity, the patient could be given the option of receiving automated responses to certain routine queries; this would remove the physician from certain highly selected communication loops. Health services and informatics methods should be applied 
to study the effect of modifying the human-computer interface on communication. There is a fine line between filtering out inappropriate communication and creating a barrier to access.

Hypotheses about the influence of e-mail on costs and use of health services must be tested rigorously. Improved access to clinicians may reduce the need for some visits. Enhanced communication about health promotion and disease prevention programs might reduce morbidity and mortality. On the other hand, e-mail communication and the formalization and documentation of the patient-physician dialogue may increase both appropriate and inappropriate use of services. Some patients may become nervous and seek urgent health care. When the dialogue appears in the written record, some physicians may be less willing to reassure patients and may have a greater tendency to recommend health care visits or diagnostic testing.

\section{Medicolegal Liability}

The use of e-mail has complex medicolegal implications. Most office staff will be unable to respond instantly to e-mail from patients. A safe and reliable system must somehow prevent the generation of messages that require urgent or emergency responses if the messages might remain unanswered for a long time. In addition, with the current proprietary e-mail systems, one party has no way of knowing whether the other has received a critical message. Again, research into the features of the human-computer interface is required. Electronic receive-and-read receipts could show both clinician and patient that important contacts were made.

The inherently superior documentation of e-mail communication compared with telephone calls, for example, could either protect against or increase physician liability. The medical community should establish guidelines for medical record storage and the organization of e-mail correspondence. Once e-mail is in widespread use between physicians and patients, surveillance should be set up that will allow the legal system to derive risk management principles specific to the new and evolving situation.

\section{Inequitable Access to Technology}

Inequitable distribution of a new technology may widen social disparities in health care access and outcomes. An effective therapy that has differential access according to socioeconomic characteristics or ethnicities may cause a divergence in health status outcomes among segments of the population (54). Although Internet access is skewed toward wealthier, more educated users $(55,56)$, market forces may shape a substantially more equitable distribution. Such businesses as telephone companies, cable television providers, technology companies, and mass media conglomerates have identified this vast market for information as a major area for investment and development. Web-browsing technology will soon be built into standard televisions. Medicine will need to adapt the technology, not create it. Penetration of this technology into the average U.S. home will probably parallel that of personal electronic items other than high-end computers. In 1995 , only $33 \%$ of U.S. homes had personal computers, but $85 \%$ had videocassette recorders and $97 \%$ had color televisions (57).

With increased use of the Internet for everyday consumer commerce, repeated predictions of widespread degradation or "brownouts" in the quality of service have been made (58). The Next Generation Internet, however, will provide a much larger transmission capacity (59). Even now, many techniques are available to improve performance of the current capacity. For example, transmission of large files (such as a cardiac angiogram) can be done during off-peak hours.

Medical systems offering electronic medical communication should research and monitor rates of access within their diverse patient populations. Cost-effectiveness analyses should establish the medical and economic advantages to the system of patient access to e-mail. The cost-effectiveness of providing technology to targeted patient populations might be studied. Even if widespread access is achieved, interface design research is still critical. If patients are required to deal with complex, poorly designed user interfaces or interfaces that require a high reading level, whole segments of the population may be cut off from the benefits of the system. Voice and video capabilities of e-mail systems could improve access for patients who are not literate.

In addition, if widespread access is to be promoted, the technology must be used sensibly. Rates of access will improve if software to communicate with a health system or physician practice is accessible from any Internet-connected device. Conversely, access will be diminished if patients are required to have specialized software on a local hard drive or a proprietary e-mail account (60).

\section{Conclusions}

E-mail between physicians and patients offers substantial promise as a way to improve access to health care, to let physicians reach out to patients, and to increase the involvement of patients in their own care. Because electronic communication between patients and providers has not yet occurred on a large scale, the opportunity still exists for patients, physicians, and software engineers to evaluate the impact that the technology will have on 
health care. The medical profession must ensure that the tools used to link physicians and patients can be used safely and appropriately by a multicultural, multilingual population with a wide range of literacy. New communication technologies must never replace the crucial interpersonal contacts that are the very basis of the patient-physician relationship. Rather, e-mail and other forms of electronic communications should be used to enhance such contacts. At this critical juncture, we have the opportunity to proceed cautiously and to collect evidence to back up our assumptions about the optimal role of e-mail between physicians and patients. It would be useful to define explicit requirements for devices that will connect providers to patients and to specify the indications for their use. The form and function of electronic communication tools and the choice of domains for their application will influence the nature of medical relationships and may ultimately affect the state of health in the United States.

Acknowledgments: The authors thank Dr. Peter Szolovits for inspiring them to explore electronic physician-patient communication and Alison Clapp, librarian at Children's Hospital, Boston, Massachusetts, for help in conducting the literature review.

Requests for Reprints: Kenneth D. Mandl, MD, MPH, Division of Emergency Medicine, MA-001, Children's Hospital, 300 Longwood Avenue, Boston, MA 02115.

Current Author Addresses: Dr. Mandl: Division of Emergency Medicine, MA-001, Children's Hospital, 300 Longwood Avenue, Boston, MA 02115.

Dr. Kohane: Division of Endocrinology, Children's Hospital, 300 Longwood Avenue, Boston, MA 02115.

Dr. Brandt: Department of Social Medicine, Harvard Medical School, 641 Huntington Avenue, Boston, MA 02115.

\section{References}

1. Fischer CS. America Calling: A Social History of the Telephone to 1940. Berkeley: Univ California Pr; 1992:176.

2. Aronson SH. The Lancet on the telephone, 1876-1975. Med Hist. 1977;21 69-87.

3. Rogers EM. Diffusion of Innovations. 4th ed. New York: Free Pr; 1995.

4. Keen J. Rethinking NHS networking. BMJ. 1998;316:1291-3.

5. Kane B, Sands DZ. Guidelines for the clinical use of electronic mail with patients. The AMIA Internet Working Group, Task Force on Guidelines for the Use of Clinic-Patient Electronic Mail. J Am Med Inform Assoc. 1998;5:104-11.

6. Glowniak JV. Medical resources on the Internet. Ann Intern Med. 1995;123: 123-31.

7. Glowniak JV, Bushway MK. Computer networks as a medical resource. Accessing and using the Internet. JAMA. 1994;271:1934-9.

8. Chi-Lum BI, Lundberg GD, Silberg WM. Physicians accessing the Internet, the PAI Project. An educational initiative [Editorial]. JAMA. 1996;275:1361-2.

9. Fraser HS, Kohane IS, Long WJ. Using the technology of the World Wide Web to manage clinical information. BMJ. 1997;314:1600-3.

10. Kassirer JR. Journals in bits and bytes. Electronic medical journals [Editorial]. N Engl J Med. 1992;326:195-7.

11. Finding help online. Consumer Reports, 1997:62:27-31

12. Ferguson T. Health Online: How to Find Health Information, Support Groups, and Self-Help Communities in Cyberspace. Reading, MA: AddisonWesley; 1996.

13. Widman LE, Tong DA. Requests for medical advice from patients and families to health care providers who publish on the World Wide Web. Arch Intern Med. 1997;157:209-12.

14. Kohane IS, van Wingerde FJ, Fackler JC, Cimino C, Kilbridge P, Murphy S, et al. Sharing electronic medical records across multiple heterogeneous and competing institutions. Proc AMIA Annu Fall Symp. 1996:608-12

15. Halamka JD, Safran C. Virtual consolidation of Boston's Beth Israel and New
England Deaconess Hospitals via the World Wide Web. Proc AMIA Annu Fall Symp. 1997:349-53.

16. Gray J, Jones PC, Phillips M, Gertman PC, Veroff D, Safran C. Telematics in the neonatal ICU and beyond: improving care for high-risk newborns and their families. Proc AMIA Annu Fall Symp. 1997:413-7.

17. Diffie W, Landau S. Privacy on the Line: The Politics of Wiretapping and Encryption. Cambridge, MA: MIT Pr; 1998.

18. Gurak L. Persuasion and Privacy in Cyberspace: The Online Protests ove Lotus Marketplace and the Clipper Chip. New Haven, CT: Yale Univ Pr; 1997

19. Jadad AR, Gagliardi A. Rating health information on the Internet: navigating to knowledge or to Babel? JAMA. 1998:279:611-4.

20. Peters R, Sikorski R. Navigating to knowledge. Tools for finding information on the Internet. JAMA. 1997;277:505-6.

21. Kassirer JP. The next transformation in the delivery of health care [Editorial]. N Engl I Med, 1995:332:52-4.

22. Miller RA, Gardner RM. Summary recommendations for responsible monitoring and regulation of clinical software systems. American Medical Informatics Association, The Computer-Based Patient Record Institute, The Medical Library Association. The Association of Academic Health Science Libraries, The American Health Information Management Association, and The American Nurses Association. Ann Intern Med. 1997;127:842-5.

23. Health Insurance Portability and Accountability Act of 1996. Public Law No. 104-191, Section 1173, USC 201. 1996

24. Weeda DF, O'Flaherty NF. Food and Drug Administration regulation of blood bank software: the new regulatory landscape for blood establishments and their vendors. Transfusion. 1998:38:86-9.

25. Wenner H. Software validation. Medical Device Technology. 1997;8:22-5

26. FDA weighs policing electronic patient record. Hosp Case Manag. 1997;5 81-3.

27. Gross TP, Kessler LG. Medical device vigilance at FDA. Stud Health Technol Inform. 1996:28:17-24.

28. Jones MG. Telemedicine and the national information infrastructure: are the realities of health care being ignored? J Am Med Inform Assoc. 1997:4:399 412.

29. Hof RD, Browder S, Elstrom P. Special report: Internet communities. Business Week. 1997; 5 May:64-92

30. Fridsma DB, Ford P, Altman R. A survey of patient access to electronic mail: attitudes, barriers, and opportunities [Abstract]. Proceedings-18th Annual Symposium on Computer Applications in Medical Care, 5-9 November 1994.

31. Neill RA, Mainous AG 3d, Clark JR, Hagen MD. The utility of electronic mail as a medium for patient-physician communication. Arch Fam Med. 1994; 3:268-71.

32. Young KT, Davis K, Schoen C, Parker S. Listening to parents. A national survey of parents with young children. Arch Pediatr Adolesc Med. 1998;152: 255-62.

33. Balas EA, Jaffrey F, Kuperman GJ, Boren SA, Brown GD, Pinciroli F, et al. Electronic communication with patients. Evaluation of distance medicine technology. JAMA. 1997;278:152-9.

34. Allely EB. Synchronous and asynchronous telemedicine. J Med Syst. 1995; 19:207-12.

35. Roter DL, Hall JA, Kern DE, Barker LR, Cole KA, Roca RP. Improving physicians' interviewing skills and reducing patients' emotional distress. A randomized clinical trial. Arch Intern Med. 1995;155:1877-84

36. Bertakis KD. The communication of information from physician to patient: a method for increasing patient retention and satisfaction. J Fam Pract. 1977; 5:217-22.

37. Greene MG, Adelman RD, Friedmann E, Charon R. Older patient satisfaction with communication during an initial medical encounter. Soc Sci Med. 1994;38:1279-88.

38. Waitzkin H. Doctor-patient communication. Clinical implications of social scientific research. JAMA. 1984:252:2441-6.

39. Korsch BM. What do patients and parents want to know? What do they need to know? Pediatrics. 1984;74(5 Pt 2):917-9.

40. Levinson W, Roter DL, Mullooly JP, Dull VT, Frankel RM. Physicianpatient communication. The relationship with malpractice claims among primary care physicians and surgeons. JAMA. 1997;277:553-9.

41. Szolovits P, Doyle J, Long WJ, Kohane I, Pauker SG. Guardian Angel: Patient-Centered Health Information Systems. Report TR-604. Cambridge, MA: MIT Laboratory for Computer Science; 1994.

42. Dertouzos ML. What Will Be: How the New World of Information Will Change Our Lives. New York: Harper Collins; 1997.

43. Slack WV, Hicks GP, Reed CE, Van Cura U. A computer-based medicalhistory system. N Engl J Med. 1966;274:194-8.

44. Bysinger B. Using the Internet to support provider-patient collaboration. Health Manag Technol. 1997; 18:44-5.

45. Gustafson DH, Hawkins RP, Boberg EW, Bricker E, Pingree S, Chan CL. The use and impact of a computer-based support system for people living with AIDS and HIV infection. Proc Annu Symp Comput Appl Med Care. 1994:604-8

46. Baer L, Jacobs DG, Cukor P, O'Laughlen J, Coyle JT, Magruder KM. Automated telephone screening survey for depression. JAMA. 1995;273:1943-4.

47. Kobak KA, Taylor LH, Dottl SL, Greist JH, Jefferson JW, Burroughs D, et al. A computer-administered telephone interview to identify mental disorders. JAMA. 1997;278:905-10

48. Linkins RW, Dini EF, Watson G, Patriarca PA. A randomized trial of the effectiveness of computer-generated telephone messages in increasing immunization visits among preschool children. Arch Pediatr Adolesc Med. 1994; 148:908-14.

49. Poole SR, Schmitt BD, Carruth T, Peterson-Smith A, Slusarski M. After- 
hours telephone coverage: the application of an area-wide telephone triage and advice system for pediatric practices. Pediatrics. 1993;92:670-9.

50. Rind DM, Kohane IS, Szolovits P, Safran C, Chueh HC, Barnett GO Maintaining the confidentiality of medical records shared over the Internet and the World Wide Web. Ann Intern Med. 1997;127:138-41.

51. Szolovits P, Kohane I. Against simple universal health identifiers, J Am Med Inform Assoc. 1994;1:316-9.

52. National Research Council. Committee on Maintaining Privacy and Security in Health Care Applications of the National Information Infrastructure. For the Record: Protecting Electronic Health Information. Washington, DC: National Academy Pr; 1997.

53. Rivest R, Shamir A, Adleman L. A method for obtaining digital signatures and public-key cryptosystems. Communications of the Association for Computing Machinery. 1978:21:120-6.

54. Hamvas A, Wise PH, Yang RK, Wampler NS, Noguchi A, Maurer MM, et al. The influence of the wider use of surfactant therapy on neonata mortality among blacks and whites. N Engl J Med. 1996;334:1635-40.

55. Hoffman DL, Novak TP. Bridging the racial divide on the Internet. Science. 1998;280:390

56. Katz J, Aspden P. Motivations for and barriers to Internet usage: results of a national public opinion survey, 1996. Available at http://www.markle.org.

57. Meeker M, DePuy C. The Internet Report-Morgan Stanley. New York: Harper Collins; 1996.

58. Metcalfe $\mathbf{B}$. Predicting the Internet's catastrophic collapse and ghost sites galore in 1996. Infoworld. 1995;4 Dec:61.

59. Ackerman M, Bailey D, DuBois R, Endicott D, Fowler J, Hui B, et al. Next Generation Internet Initiative: NGI Implementation Plan. Arlington, VA: National Coordination Office for Computing, Information, and Communications; 1998. Available at http://www.ccic.gov/ngi/implementation/.

60. MandI KD, Katz SB, Kohane IS. Social equity and access to the World Wide Web and e-mail: implications for design and implementation of medical applications. Proc AMIA Annu Fall Symp. 1998; [In press].

When he got warm, he got happy again. Several years ago Dr. Hawkins, who treated both Hellman and Sylvia on the ridge and then in the hospital, told me that, if I were burned and wanted to be as happy as Joe Sylvia had been, I should get terribly burned. "Then," he said, "your sensory apparatus dumps into your bloodstream." He added, "Usually it takes until the next day to clog your kidneys. In the meantime, it is possible to have spells when you think you are happy."

Norman Maclean

Young Men and Fire

Chicago: Univ of Chicago Pr; 1992

Submitted by:

Malcolm L. Brigden, MD

Kelowna, British Columbia, Canada

Submissions from readers are welcomed. If the quotation is published, the sender's name will be acknowledged. Please include a complete citation, as done for any reference.-The Editor 
Copyright of Annals of Internal Medicine is the property of American College of Physicians and its content may not be copied or emailed to multiple sites or posted to a listserv without the copyright holder's express written permission. However, users may print, download, or email articles for individual use. 